\title{
Çok Katlı Binalarda Gri Suyun Yerinde Arıtılması ile Yeniden Kullanılmasının Fizibilitesi: İstanbul'da Bir Kentsel Dönüşüm Projesi Örneği
}

\author{
The Feasibility of On-site Greywater Treatment for Non- \\ Potable Reuse in Multi-Storey Buildings: A Case of Urban \\ Transformation Project in Istanbul
}

\author{
Börte Köse-Mutlu 1,2*(D) \\ 1 İnşaat Mühendisliği Bölümü, Mühendislik Fakültesi, Yeditepe Üniversitesi, 34755, Ataşehir, İstanbul, TÜRKiYE \\ 2 Prof. Dr. Dincer Topacık Ulusal Membran Teknolojileri Uygulama ve Araştırma Merkezi, İstanbul Teknik Üniversitesi, \\ 34467, Sarıyer, İstanbul, TÜRKIYE \\ Sorumlu Yazar / Corresponding Author*: kosebo@itu.edu.tr
}

\section{Geliș Tarihi / Received: 30.03.2020 Araștırma Makalesi/Research Article Kabul Tarihi / Accepted: 11.07.2020 DOI:10.21205/deufmd.2021236707}

Atıf șekli/How to cite: KÖSE-MUTLU, B., Çok Katlı Binalarda Gri Suyun Yerinde Arıtılması ile Yeniden Kullanılmasının Fizibilitesi: İstanbul'da Bir Kentsel Dönüşüm Projesi Örneği, DEUFMD, 23(67), 81-91.

Öz

Su kıtlığının en önemli konulardan biri olduğu günümüz dünyasında atıksuyun yeniden kullanılması sorunu çözmenin anahtarı olarak görülmektedir. En uygun yöntem ise nispeten düşük kirliliğe sahip olan gri suyu, kanalizasyon sistemine dahil olmadan toplayabilmektir. Mutfak ve banyolardan toplanan gri su, ortak bir arıtma tesisinde arıtıldıktan sonra sifonlarda kullanılmak üzere bireysel kullanıcılara sunulabilir. Bu çalışmada kullanılan bina modelinde aynı katta yer alan dairelerin tuvaletleri dikey eksende birbirlerine yakın bir şekilde konumlandırılmıştır. Böylece atıksuların toplanması için gerekli altyapı borularının uzunluğu en az seviyede tutulabilmiștir. Arıtılmıș suyun yeniden kullanılması, mevcut hatlara gri su hatlarının ilavesi ile mümkün olacaktır. Çalışmada, yüksek binalarda inşa edilecek ilave hatların ve kurulacak arıtma tesislerinin ilk yatırım ile işletme ve bakım maliyetleri hesaplanarak sunulmuştur. Arıtma teknolojisi seçenekleri olarak döner biyodisk, membran biyoreaktör ve nanofiltrasyon sistemleri karşılaştırmalı olarak değerlendirilmiştir. Özellikle 160 ve daha fazla daireye sahip çok bloklu veya yüksek katlı binalarda gri suyun kullanımı fizıbıl bulunmakla beraber, en yüksek fayda-maliyet oranına sahip arıtma teknolojisinin nanofiltrasyon sistemi olduğu sonucuna varılmıştır.

Anahtar Kelimeler: Gri Su; Arıtma; Yeniden Kullanım; Fizibilite; Membran Prosesler.

\begin{abstract}
In today's world, where water scarcity is one of the most important issues, the reuse of wastewater is seen as the key to solve the problem. The most proper solution is to collect greywater, which has relatively low pollution, separately before entering the sewer system. The greywater collected from kitchens and bathrooms can be served to the individual users and it can be used as flush water after being treated in a common treatment plant. In the model building studied in this paper, the toilets of the apartments on the same floor were located close to the vertical shift, so that the length of the pipes for additional infrastructure required for the collection of wastewater was minimal. The reuse of the
\end{abstract}


treated water was also possible when greywater lines were added to the existing lines. In the study, capital and operation and maintenance costs of these infrastructures and treatment plant to be constructed are presented. The treatment alternatives that had been comparatively evaluated were rotating biodisc, membrane bioreactor, and nanofiltration systems. To conclude, it was found feasible to use greywater especially in multi-block and/or high-rise buildings with 160 or more apartments, at the same time it is concluded that the treatment technology with the highest benefit-cost ratio is the nanofiltration system.

Keywords: Greywater; Treatment; Reuse; Feasibility; Membrane Processes.

\section{Terimler Dizini ve Kısaltmalar}

\begin{tabular}{|c|c|}
\hline CEPCI & $\begin{array}{l}\text { Chemical engineering plant cost } \\
\text { index (Kimya mühendisliği tesis } \\
\text { maliyetleri endeksi) }\end{array}$ \\
\hline EM $_{\text {AAT }}$ & $\begin{array}{l}\text { Gri su arıtımı için ortaya çıkan } \\
\text { enerji sarfiyatından oluşan } \\
\text { maliyet }\end{array}$ \\
\hline EMPompa & $\begin{array}{l}\text { gri suyun terfisi için gereken } \\
\text { enerji sebebiyle ortaya çıan } \\
\text { maliyet }\end{array}$ \\
\hline $\mathrm{F}: \mathrm{M}$ & Fayfa/maliyet oranı \\
\hline GüçMBR & $\begin{array}{l}\text { MBR sistemindeki güç } \\
\text { gereksinimi }\end{array}$ \\
\hline İBM & İşletme ve bakım maliyeti \\
\hline İBM & $\begin{array}{l}\text { RBC sistemlerindeki ek } \\
\text { maliyetleri kapsayan diğer } \\
\text { maliyetler }\end{array}$ \\
\hline İBMкіm & Kimyasal maliyetleri \\
\hline İSKİ & $\begin{array}{l}\text { İstanbul Su ve Kanalizasyon } \\
\text { İdaresi }\end{array}$ \\
\hline İYM & İlk yatırım maliyeti \\
\hline IYYM ${ }_{\text {Boru }}$ & Borular için gereken IYM \\
\hline İYMKlor & Dezenfeksiyon için gereken IYYM \\
\hline IYYM $_{\text {MBR }}$ & MBR için gereken IYM \\
\hline $\begin{array}{l}\text { IYYM }_{\text {NF-I- }} \\
\text { IYYM } \\
\text { NF-V }\end{array}$ & $\begin{array}{l}\text { Boru ve vana, enstrümentasyon } \\
\text { ve kontrol, tank ve çerçeve, } \\
\text { diğer ve son olarak pompa için } \\
\text { IYYM }\end{array}$ \\
\hline İYMPompa & Pompalar için gereken IYYM \\
\hline $\mathrm{I}_{\mathrm{Y}} \mathrm{M}_{\mathrm{RBC}}$ & RBC için gereken IYM \\
\hline İYM & Tanklar için gereken İYM \\
\hline IYYM $_{\text {Toplam }}$ & Toplam IYM \\
\hline KOİ & Kimyasal oksijen ihtiyacı \\
\hline MBR & Membran biyoreaktör \\
\hline NF & Nanofiltrasyon \\
\hline $\mathrm{RBC}$ & Döner biyoreaktör \\
\hline SF & Bir dairenin yıllık su faturası \\
\hline
\end{tabular}

\begin{tabular}{|l|l|}
\hline $\mathrm{SF}_{\mathrm{az}}$ & $\begin{array}{l}\text { Bir dairenin yıllık su } \\
\text { faturasındaki azalma } \\
\text { Daire başına su faturasındaki } \\
\text { tasarruf }\end{array}$ \\
$\mathrm{SS}_{\mathrm{AY}}$ & Aylık su sarfiyatı \\
$\mathrm{SS}_{\text {kişi }}$ & Su sarfiyatı \\
$\mathrm{ST}_{\text {Gri-ay }}$ & $\begin{array}{l}\text { Gri suyun sifonlarda } \\
\text { kullanılmasıyla gerçekleșen } \\
\text { aylık su tasarrufu }\end{array}$ \\
& \\
\hline
\end{tabular}

\section{Giriş}

Eskiden su zengini olduğu düşünülen pek çok ülke için günümüzde su kıtlığı söz konusudur. Evsel, endüstriyel ve tarımsal kullanım amaciyla su teminine olan ihtiyacın her geçen gün artması mevcut küresel ısınmanın da etkisi ile ülkelerde su stresine neden olmaktadır. Su kıtlı̆̆ı problemi için anahtar çözüm, sürdürülebilir su yönetiminin başarılı bir șekilde gerçekleștirilebilmesidir. Bu bağlamda, evsel atıksuyun karakterizasyonlarına bağlı olarak ayrık akımlar (örneğin; gri su, siyah su gibi) halinde toplanmasına dayanan prensip yenilikçi bir fikir olarak karșımıza çıkmaktadır. Özellikle İstanbul gibi büyük şehirlerde artan su talebi ile bahsedilebilmesi adına ortaya konulan su yönetim stratejilerinde gri suyun yeniden kullanımı öne çlkan bir seçenektir. Gri su, küvet ve duşa kabinlerden, banyo lavabolarından, çamaşır yıkama ve kurutma ünitelerinden ve mutfak lavabolarından toplanan atıksuları içermektedir. Gri su, diğer ayrık akımlara görece daha büyük hacimlerde ortaya çıkar ve kirlilik seviyesi de daha düșüktür [1]. Gelișmiș ülkelerde kişi başı günlük 100-150 L mertebelerinde oluşan evsel atıksuyun hacimce \%60-70'lik bir kısmı aslında gri sudan oluşur [2]. Başarılı bir şekilde toplanıp uygun teknolojilerle arıtılabilen gri sular, tuvaletlerde sifon suyu olarak kullanılabilir. 
DEÜ FMD 23(67), 81-91, 2021

Gri su, yüksek kirlilik içermeyen bir atıksu olarak sınıflandırılsa da Kimyasal Oksijen İhtiyacı (KOİ) konsantrasyonu yüzlerce $\mathrm{mg}$ /L'ye ulaşabilmektedir. Ayrıca, $10^{4}-10^{6} \mathrm{CFU} / \mathrm{ml}$ fekal koliform da içermektedir. Dolayısı ile gri suyun arıtılmadan kullanılması durumunda önemli sağlık riskleri ortaya çıkabilir. Özellikle yaz aylarında patojen üremesinin önüne geçebilmek adına binalarda yüksek verimlerde arıtma yapabilen sistemlerin kurulmuş olması gerekmektedir [3,4]. Gri suyun yeniden kullanımı için fiziksel, kimyasal veya biyolojik proseslere dayalı aritma teknolojileri kullanılmaktadır. Pek çok çeșidi olan biyolojik arıtma teknolojileri içerinde Döner Biyoreaktör (Rotating Bioreactor, RBC) en etkili olan teknolojilerden biridir [5-7]. Friedler ve arkadaşlarının çalışmalarında altını çizdikleri üzere RBC kullanımı ile düșük enerji sarfiyatları ve düşük işletme maliyetleri elde edilebilmektedir [5]. Araştırmacılar bu çalıșmalarında klorlama ile kombinlenmiș bir RBC kullanarak ilgili standartlarda belirtilen çıkış suyu değerlerine ulaşabilmişlerdir. Membran Biyoreaktör (Membrane Bioreactor, MBR) kullanımı da öne çıkan bir diğer fizibıl seçenektir [8-11]. Gri su bünyesinde üreyi barındırmadığı için (üre içeren akım sarı su olarak isimlendirilmektedir) biyolojik aritma proseslerinde azot, limitleyici element olarak davranabilir ve arıtma verimleri bu durumdan etkilenebilir [12]. Dolayısı ile, Nanofiltrasyon (NF) gibi membran teknolojileri de gri suyun arıtılarak tekrar kullanımında etkili bir çözüm seçeneği olabilir [13-15].

Gri suyun yeniden kullanımı çok katlı binaların İlk Yatırım Maliyetlerini (IYM) arttıracaktır. Gri suyun yeniden kullanımı için kurulacak bir sistem, gri suyun küvet, duș, çamașır makinesi ve diğer ilgili ünitelerin çıkışından toplanması için gereken ayrık toplama hatlarının inșasını gerektirir. Buna ek olarak, toplanan gri suyun depolanması için tankların alınması gerekmektedir. Bu tanklar belli bir yer de işgal edecektir [16]. Bu makalede, İstanbul'da yer alan çok katlı binalarda gri suyun yeniden kullanımının ekonomik analizi yapılmıştır. $\mathrm{Bu}$ fizibilite analizinde, bireysel kullanıcının faydaları da göz önüne alınarak bir yeniden kullanım projesinin binanın IYM ve İşletme ve Bakım Maliyetleri (İBM) üzerindeki arttırıcı etkisi ortaya konulmuștur. Bu bağlamda, üç farklı arıtma teknolojisi (RBC, MBR ve NF) kullanıldığında elde edilen daire başına spesifik maliyet ve ilave maliyetlerin binanın toplam maliyeti içerisindeki oranı da hesaplanmıștır. Ayrıca, her arıtma teknolojisi için İBM değerleri harcama kalemleri bazında karşılaştırmalı olarak değerlendirilmiştir.

\section{Materyal ve Metot}

\subsection{Bina ve altyapı sistemlerinin özellikleri}

Bu çalışma, kat sayısı ondan fazla olan yüksek binalar için gerçekleștirilmiștir. Her kattaki daire sayısı 4, bir dairede yaşan aile büyüklüğü ise 3,4 kişi/daire olarak kabul edilmiştir [17]. Binada kat yüksekliği 3 m'dir. Dairelerdeki banyolar ve tuvaletler, binalardaki dikey şafta yakın şekilde konumlandırılmıștır. Bu çalışmada tasarlanan gri su sisteminin üç ana altyapı bileşeni bulunmaktadır: 1) Gri suyu toplama hatları, 2) arıtılmış atıksuyun depolama tankına aktarılması ve 3) arıtılmış gri suyun depolama tankından dairelere dağılması için kullanılan hatlar. Öncelikle, duşlardan ve lavabolardan toplanan sular yatay borular ile daire içerisinde ilerledikten sonra merkezi dikey kolektör vasıtası ile bodrum katına aktarılır. Bodrum katında kurulmuş olan bir paket arıtma sisteminde arıtılmasının ardından bodrum katında yer alan depolama tankına muhafaza edilir. Arıtılan gri su dairelere pompa vasita ile geri gönderilir. Tasarlanan bu sistemde konvansiyonel altyapıya ek olarak iki yeni altyapı ögesi söz konusudur. Birincisi, yukarıda bahsi geçen daire içerisi yatay toplama hatlarıdır. İkincisi ise arıtılmıs suyu daire içerisindeki sifon depolarına ileten yatay iletim hattıdır. Gri suyun yeniden kullanımı hedeflendiğinde bu iki yeni hat, tasarıma ve inşa süreçlerine dahil edilmelidir. Arıtılmış su en üst kata terfi edildikten sonra diğer katlara cazibe ile aktarılacaktır. Gri suyun toplanması ve dağıtılması için gereken daire içi ve daire dışı boru uzunlukları sırası ile 5,0 ve 9,0 m'dir [18]. 9 m'lik daire dışı boru elemanları 3'er m olarak toplama, depolama tankına pompaj ve dağıtım amacı ile ișletilecektir. Depolama tankı adedi iki olup biri toplanmış gri suyun depolanması diğeri ise arıtılmış gri suyun depolanması için kullanılacaktır. Her bir depolama tankının hacmi $1 \mathrm{~m}^{3}$ 'tür [18]. Tüm sistemin özetlendiği temsili bina görseli Şekil 1'de verilmektedir.

\subsection{Gri su arıtma teknolojileri}

Maliyet analizleri üç farklı arıtma teknolojisinin kullanılması durumu için gerçekleştirilmiştir: bir RBC sistemi, bir MBR sistemi ve bir NF sistemi. 
DEÜ FMD 23(67), 81-91, 2021

Arıtma sistemlerinin konfigürasyonu Șekil 2'de verilmektedir. Gri su arıtma sistemlerinin işletme koşulları ise Tablo 1'de sunulmuştur.

\subsection{Maliyet analizi \\ 2.3.1 Maliyetler}

$\mathrm{Bu}$ çalışmada gerçekleştirilen maliyet analizi hesaplamaları IYYM ve İBM kalemlerinin tümünü içermektedir. Birim debi veya birim membran alanı tabanlı denklemler kullanılarak IYM hesaplanmıștır. Çeșitli sistem elemanlarının (örneğin; NF membranı) yatırım maliyetleri üretici ve sağlayıcılardan elde edilmiştir. IYM; altyapının inşaatı, arıtma sistemleri ve ek giderleri içerir.

IYYM hesaplarında kullanılan denklemler aşağıda sunulmaktadır (Denklem 1-12). Altyapı maliyetleri, Denklem 1 ve gereken boru uzunluğu kullanılarak hesaplanmıştır. RBC ve MBR sistemlerinin IYM değerleri ise sırası ile Denklem 3 ve Denklem 4 yardımı ile hesaplanmıştır.

Tablo 1. Arıtma sistemlerinin işletme koşulları.

\begin{tabular}{|c|c|c|}
\hline Parametre & Birim & Değer \\
\hline $\mathrm{Ak}_{\mathrm{MBR}}$ & $\mathrm{L} / \mathrm{m}^{2} / \mathrm{sa}$ & 32,0 \\
\hline $\begin{array}{l}\text { MBR Tank boyutları } \\
\text { (Yükseklik x En x Boy) }\end{array}$ & $\mathrm{m}$ & $1,85 \times 0,80 \times 1,20$ \\
\hline $\mathrm{Ak}_{\mathrm{NF}}$ & $\mathrm{L} / \mathrm{m}^{2} / \mathrm{sa}$ & 60,0 \\
\hline NF işletme basıncı & bar & 12,0 \\
\hline İşçilik $k_{R B C}$ & sa/hafta & 7,0 \\
\hline İşçilikMBR & sa/hafta & 2,0 \\
\hline
\end{tabular}

(gerekebilecek ufak cihazlar, vanalar, bağlantılar vb.) toplam maliyetim \%15'i kadarı da IYYM'ne eklenmiştir. Denklem 3 ve 4 , bu ek giderleri barındırmamaktadır. Diğer yandan, Denklem 610 kullanıldığında NF sistemi için ek maliyetleri kapsamaktadır. Bir klorlama ünitesi için gereken IYYM, tüm arıtma teknolojileri için aynı olduğu kabulü ile toplam IYM'nin hesabında kullanılmıștır. Klorlama için gereken IYM, değișen kapasite ile değişkenlik göstermemektedir. IYYM değerleri Chemical Engineering Plant Cost Index (CEPCI) kullanılarak güncellenmiştir. IYYM değerlerinin yıllık değere indirgenmesinde kullanılan aylık net faiz oranı 0.083 olup ve maliyet analizi süresi olarak 15 yll tercih edilmiștir. Son olarak, arazi maliyeti $2163 \$ / \mathrm{m}^{2}$ kabul edilmiştir. RBC ve MBR sistemleri için kullanılan denklemler Friedler ve Hadari'nin yayınından, NF sistemi için kullanılan denklemler ise yazarın daha önce yayınlanmıș makalesinden alınmıștır $[18,19]$. IYYM değerlerinin yıllık değerlere çekilmesinde kullanılan formüller ve katsayılar "Mühendislik Ekonomisi" kitabından elde edilmiştir [20].

İBM ise enerji, işçilik ve kimyasal maliyetlerini içermektedir. Birim elektrik ve işçilik maliyetleri sırası ile 0,76 \$/kW.sa ve 2,05 \$/sa șeklindedir. Giriș klor konsantrasyonu 3,0 mg/L iken çıkıș klor konsantrasyonu 1,0 mg/L olarak işlemler yapılmıştır. Klorlama maliyeti için kimyasal ücretleri üreticilerden sağlanmıştır [21]. RBC sistemi için güç sarfiyatı ve enerji maliyeti literatürde yer alan Denklem 12 kullanılarak hesaplanmıştır [18].

MBR sisteminde ortaya çıkan enerji sarfiyatı, Davies'in yayınladığı çalışmada yer alan birim maliyet $\left(1,25 \mathrm{~kW} . \mathrm{sa} / \mathrm{m}^{3}\right.$ arıtılmış gri su) kullanılarak hesaplanmıștır [22]. MBR sistemleri genellikle önleyici bakımlara ihtiyaç duyarlar ve bu ek bir İBM oluşturur. Bu maliyet, 0,025 $\$ / \mathrm{m}^{3} /$ yll olarak kabul edilmiștir. Diğer yandan NF için İBM hesaplamaları 0,12 \$/ $\mathrm{m}^{3}$ kabulü ile gerçekleştirilmiştir [23]. Son olarak, arıtılmış gri suyun iletimi için gerekli enerji ise Bölüm 2.1'de detayları verilen bina özellikleri baz alınarak hesaplanmıştır.

\subsubsection{Faydalar}

Gri suyun yeniden kullanımı, bireysel kullanıcı için hem fayda hem de maliyet anlamına gelmektedir. Maliyet analizinde, daire başına birim fiyat ortaya konulur iken hem maliyetler hem de faydalar ayrıca hesaplanmıștır. Dairede ikamet eden her aile gri suyun sifon suyu olarak yeniden kullanımı sayesinde su sarfiyatını azaltacağından aylık su ve atıksu bedelleri faturaya daha düșük yansıyacaktır. Bir bina için toplam yıllık net tasarruf çeşitli bina modelleri için (kat sayılarının arttırılması ile) hesaplanarak son spesifik maliyetler (IYM \$/daire) ve oransal maliyetler karşılaștırmalı sunulmuştur. Birim su ve atıksu hizmet bedelleri İstanbul $\mathrm{Su}$ ve Kanalizasyon İdaresi (ISSKI)'nin 2019 yll maliyetleri olan $0,96 \$ / \mathrm{m}^{3}$ /ay ve 0,34 $\$ / \mathrm{m}^{3}$ /ay olarak hesaplamaya dahil edilmiștir [24]. 


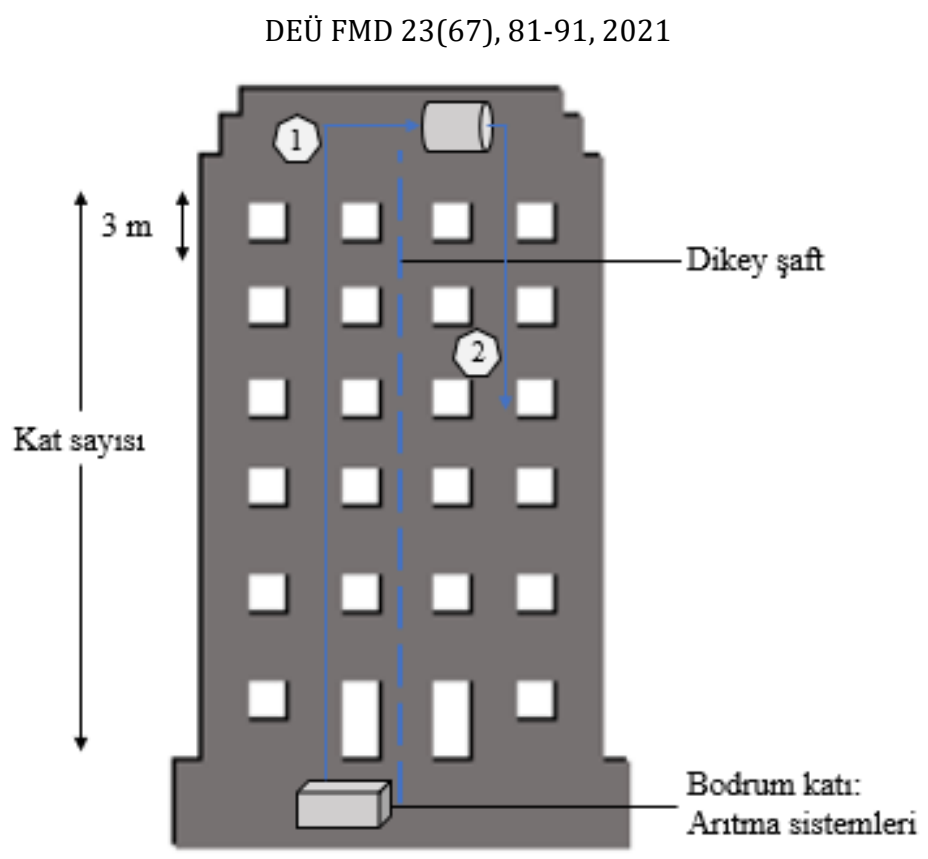

Şekil 1. Fizibilite çalışmasında kullanılan bina modeli: (1) Arıtılmış gri suyun bodrum katından depoya iletilmesi ve (2) depodan dairelere aktarımı
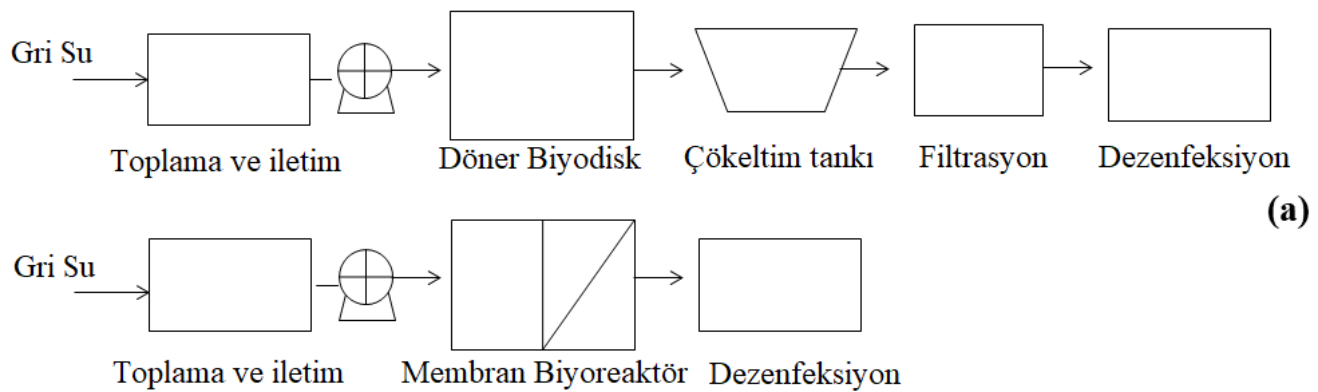

(a)

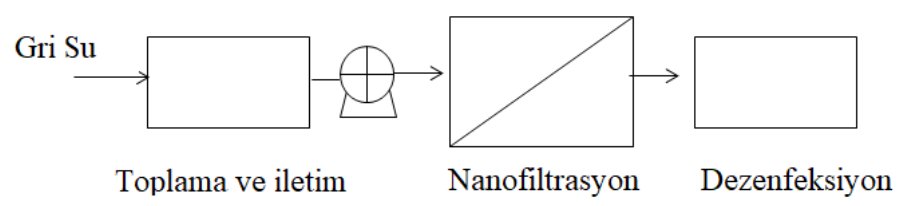

(b)

(c)

Şekil 2. Gri su aritma teknolojileri: (a) RBC, (b) MBR ve (c) NF 
DEÜ FMD 23(67), 81-91, 2021

\section{Denklem*}

IYYM ${ }_{\text {Boru }}=6 * \mathrm{~L}$

IYYM $_{\text {Tank }}=144 * V^{0,484}$

IYYM $_{\text {Pompa }}=594 * Q^{0,0286}$

IYYMRBC $_{\mathrm{RBC}}=18,853+17,945^{*} \operatorname{Ln}(\mathrm{Q})$

IYYM $_{\text {MBR }}=3,590^{*} Q^{0,6776}$

IYYMNF-I $=5926,13^{*} A^{0,42}$

IYYM $_{\text {NF-II }}=1445,5^{*} A^{0,66}$

IYYM $_{\text {NF-III }}=3047,21^{*} A^{0,53}$

IYYM $_{\mathrm{NF}-\mathrm{IV}}=7865,02^{*} A^{0,57}$

IYYMNF-V $=389,12^{*}(\mathrm{Q} / 24 *(P *$ $100)^{0,39}$

IYYM $_{\text {Klor }}=1.670$

Gü ÇMBR $=42,2 * e^{(0,1046 * Q)}$

\section{Öge/Baz/Birim}

Boru/Uzunluk/\$/m

Depolama tankı/Hacim $/ \$ / \mathrm{m}^{3}$

Pompa/Debi $\$ / \mathrm{m}^{3} /$ gün

$\mathrm{RBC} / \mathrm{Debi} / \$ / \mathrm{m}^{3} /$ gün

MBR/Debi/ $\$ / \mathrm{m}^{3} /$ gün

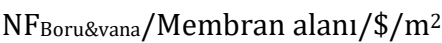

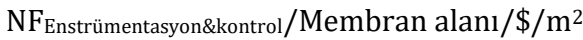

$\mathrm{NF}_{\text {Tank\&çerçeve }} /$ Membran alanı $/ \$ / \mathrm{m}^{2}$

$\mathrm{NF}_{\text {Diğer }} /$ Membran alanı $/ \$ / \mathrm{m}^{2}$

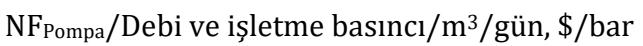

Klorlaman/Ünite/\$ünite

MBR/Debi/ $\$ / \mathrm{m}^{3} /$ gün

${ }^{*}$ L: uzunluk, V: hacim, Q: debi ve P: basinç ifade etmektedir.

Birim daire fiyatları için ise kentsel dönüşüm sonrası Fikirtepe'de satıșa sunulan dairelerin fiyatları kullanılmıștır [25]. Tüm fayda ve maliyetlerin şematik anlatımı Şekil 3'te gösterilmektedir.

\section{Bulgular}

Tüm arıtma sistemleri için spesifik maliyetler Şekil 4'te sunulmaktadır. RBC sistemi için IYM değerlerinin daire sayısının değişiminden etkilenme oranı MBR ve NF sistemleri ile karşılaştırıldığında daha yüksek seyretmiştir. Kısaca daire bașına düșen IYM olarak tanımlanabilen spesifik maliyet, RBC sistemi tercih edildiğinde ancak 80 dairelik bir binada 1000 \$/daire'nin altına inebilmektedir. Bu daire sayısı, bu çalışmada kullanılan bina modeline göre 20 katlı bir binaya tekabül etmektedir. Öte yandan, MBR ve NF sistemleri tercih edildiğinde binanın yüksekliğinden bağımsız olarak spesifik maliyetler 1000 \$/daire'den daha düşüktür. Belli bir limit noktasına kadar RBC sisteminin IYM değerleri, kişi sayısı ve gri su debisinden bağımsız ilerlemiștir. Membran sistemleri ise debiye daha bağlı bir davranış sergilemiş ve küçük kapasiteler için daha uygun oldukları görülmüștür. Beklenildiği üzere, spesifik maliyetler artan daire sayısı ile azalmıștır. $\mathrm{Bu}$ sonuç ışığında, yüksek binaların gri suyun yeniden kullanımı adına daha müsait olduğu söylenebilir. IYYM değerleri göz önüne alındığında en fizibıl arıtma sistemi, MBR olmuştur. $\mathrm{Bu}$ sonuç, literatürde daha önce sunulan sonuçlar ile karșılaștırıldığında farklılık göstermiștir [18]. Gözlenen fark, membran teknolojisinin maliyetlerinin yllar içerisinde azalması ile açıklanabilir.

Oransal ilk yatırım maliyetleri ise Şekil 5'te sunulmaktadır. Oransal maliyetler, arıtma sisteminin maliyetinin daire fiyatına oranlanması ile elde edilir ve yüzdesel bazda ifade edilir. Bu parametrenin sunulması IYM değerlerinin sağlıklı bir șekilde yorumlanabilmesi için gereklidir. Oransal maliyetler hesaplanırken İstanbul'da yer alan ve önemli bir kentsel dönüșüm projesi örneği olan Fikirtepe kentsel dönüșüm alanında inşa edilmiș binaların satıș fiyatları kullanılmıștır. İlgili projedeki $1+1,2+1$ ve $3+1$ dairelerin ortalama fiyat 155.000 \$ olarak belirlenmiştir [25]. Grafik incelendiğinde, artan daire sayısı ile oransal IYYM'nin de azaldığı görülmektedir. Yüksek olmayan binalarda MBR ve NF sistemlerinin oransal IYM değerleri birbirlerine yakınken yüksek binalarda MBR sisteminin daha fizibıl olduğu görülmüștür. RBC sisteminin IYYM değerleri binanın ederi ile kıyaslandığında 
DEÜ FMD 23(67), 81-91, 2021
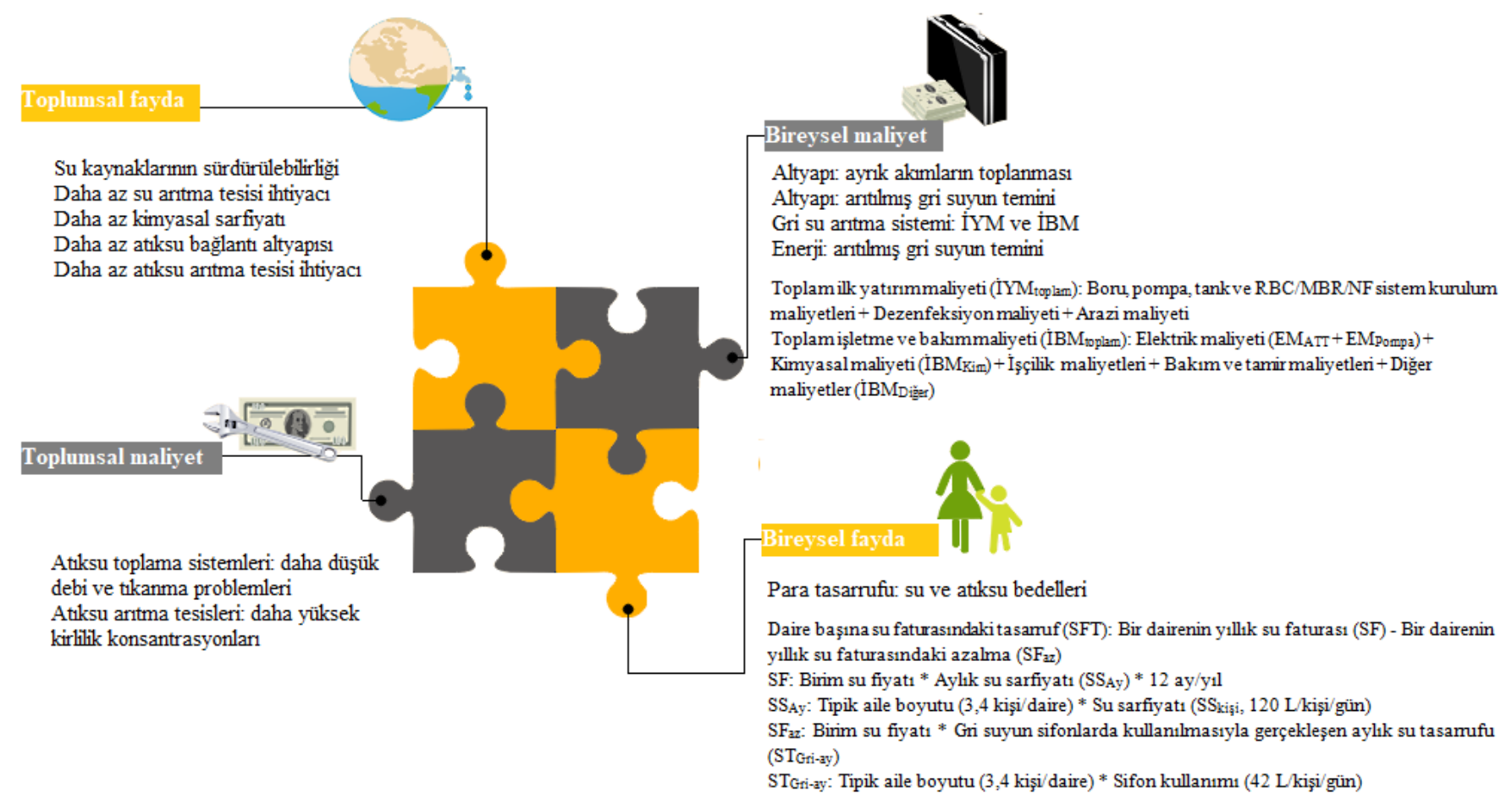

Şekil 3. Bireysel kullanıcı için fayda ve maliyetler ([18] numaralı kaynaktan yararlanarak şematize edilmiş ve matematiksel ilişkiler eklenerek revize edilmiştir). 
DEÜ FMD 23(67), 81-91, 2021

yüksek kalmıștır. RBC sistemleri için oransal IYM tüm binalar için \%0,5'ten yüksek iken, MBR sistemi tercih edildiğinde bu değer her durumda $\% 0,4$ 'ten düşük kalmaktadır. Özellikle bina 3040 kattan daha fazla katlıysa MBR kullanımı maliyetlerinde önemli bir düşüş gözlenmiştir. $\mathrm{Bu}$ sonuç doğrultusunda, MBR sistemlerinin özellikle gökdelenler için uygun olacağı söylenebilir.

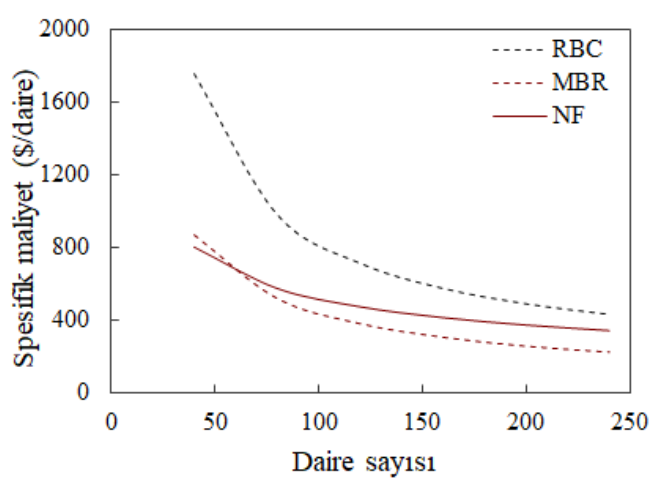

Şekil 4. Tüm arıtma ve yeniden kullanım maliyetlerini içeren spesifik IYYM değerlerinin RBC, MBR ve NF sistemleri için değişimi

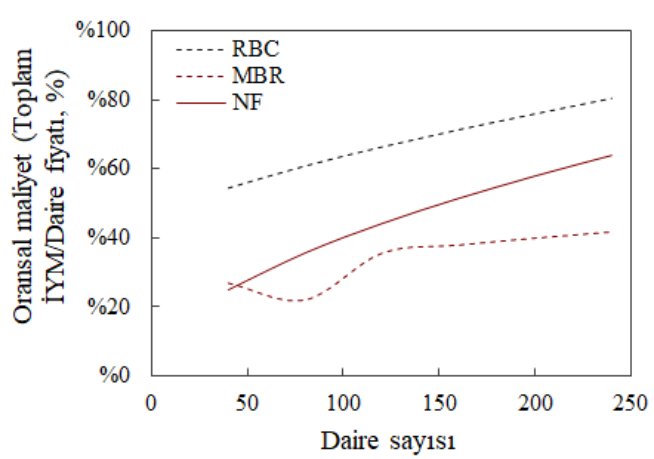

Şekil 5. Tüm arıtma ve yeniden kullanım maliyetlerini içeren oransal IYYM değerlerinin

RBC, MBR ve NF sistemleri için değişimi

İşletme ve bakım maliyetleri, tüm maliyet bileșenlerinin de ayrı ayrı gösterilmesi ile sunulmaktadır (Şekil 6). İBM içerisinde en yüksek orana sahip maliyet kalemi arıtılmış gri suyun bodrum katından en üst kattaki depoya terfisi için gereken enerji sebebiyle ortaya çıkan enerji maliyetidir. RBC sistemlerindeki ek maliyetleri kapsayan diğer (İBMDiğer) maliyetler kalemi, diğer sistemler ile karşılaștırıldığında yüksek çıkmıştır. Kimyasal maliyetleri (İBM Kim $_{\text {) }}$ ise tüm arıtma sistemi seçenekleri için düşük seviyelerde seyretmiștir.

Gri su arıtımı için ortaya çıkan enerji sarfiyatından oluşan maliyet (EM $\mathrm{EAT}_{\mathrm{AT}}$ )'in toplam IBM içerisindeki oranı, arıtma sistem seçenekleri içerisinde $\quad \mathrm{RBC}>\mathrm{MBR}>\mathrm{NF} \quad$ şeklinde sıralanmaktadır. Arıtma için harcanan en yüksek enerji miktarı RBC sistemi kullanımındadır. RBC sistemi kullanımında İBMDiğer maliyet kalemi binanın kat sayısının artışı ile azalıș göstermekteyken aynı sistemde $\mathrm{EM}_{\mathrm{AAT}}$ ise binanın kat sayısına bağlı olarak artmaktadır. Daha sağlıklı bir değerlendirme yapabilmek adına, EMAAT'ye ek olarak arıtılmış gri suyun terfisi için gereken enerji sebebiyle ortaya çıkan maliyet (EMPompa) de ayrica sunulmuştur. Özellikle NF sisteminde İBM Diğer, İBMKim ve EM $_{\text {AAT'nin }}$ toplam İBM içerisindeki oranı EMPompa'nın toplam İBM içerisindeki oranı ile kıyaslandığında düșük kalmaktadır.

Bu durumda terfi için gereken enerjinin yüksek olması problemi için en uygun çözüm her on katta bir servis katı inşa edilmesidir. Paket arıtma sisteminin servis katlarına da kurulumu ilave maliyet anlamına da gelmektedir. Dolayısı ile her kattaki nüfus yoğunluğunun arttırılması daha doğru bir yaklașım olacaktır. Bir binadaki daire sayısının en fazla, kat sayısının en az olduğu bina modelleri tasarlanmalıdır. Tüm bunlara ek olarak, yıllık net tasarruf ve mali geri dönüş bilgileri en fizibıl arıtma sistem seçeneği olan NF için Şekil 7'de verilmektedir.

Fayda/maliyet (F:M) oranları irdelendiğinde ise 40 adet daire sayısına sahip bir bina modelinde RBC, MBR ve NF sistemleri için sırası ile $0,2,0,2$ ve 0,5 iken daire sayısının artıșı ile beraber NF sistemine ait F:M oranlarında önemli bir artış gözlenirken RBC ve MBR sistemleri için aynı artış söz konusu olamadığı gözlenmiştir. Tüm yerleşim modelleri için NF sisteminin F:M oranı diğer sistemlerin F:M oranlarından daha yüksek seyretmiștir ve 160 dairelik bir yerleşimde NF sisteminin F:M oranı 1'den büyüktür. Bunlara ek olarak, yıllık net tasarruf artan daire sayısı ile artmakta iken mali geri dönüş ise yüksek binalarda daha kısa sürede gerçekleşmektedir. Dolayısı ile her ne kadar EMpompa değerleri yüksek olsa da seçilecek olan sistem paket bir NF sistemi olmalıdır. 
DEÜ FMD 23(67), 81-91, 2021

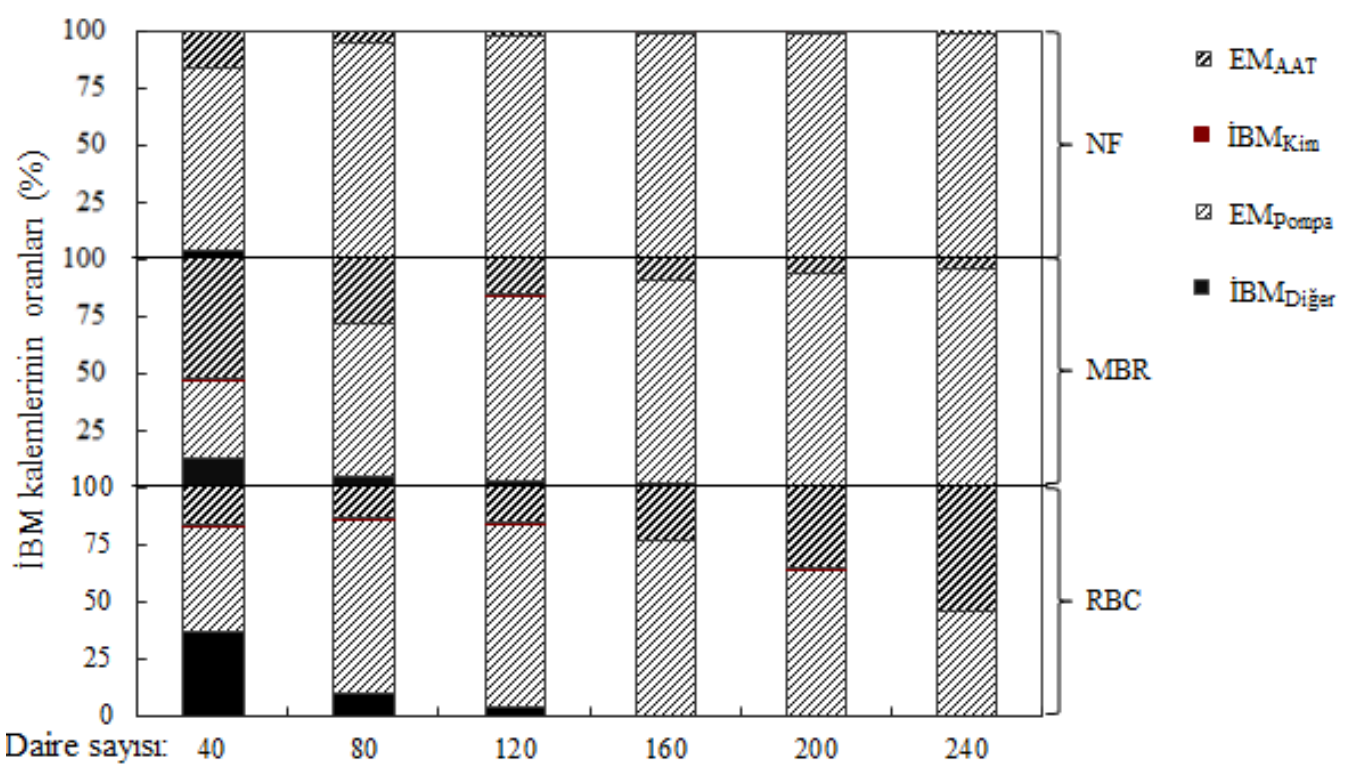

Şekil 6. Tüm arıtma sistemleri için oransal İBM değerleri

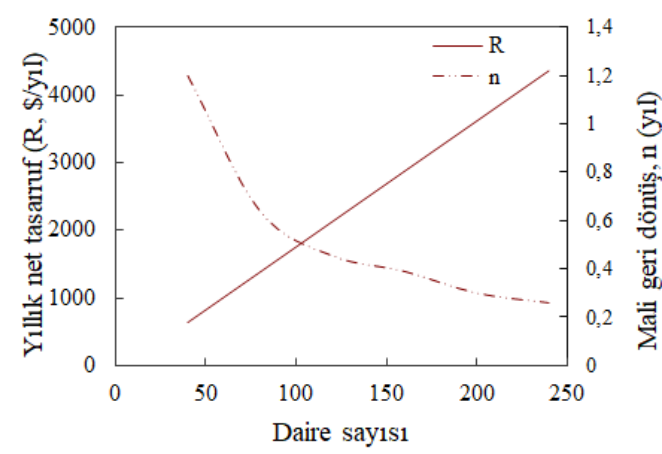

Șekil 7. Çok katlı binalarda NF sistemi kullanımı için yıllık net tasarruf ve mali geri dönüş değerleri

Son olarak, mühendislik projelerinde seçeneklerin değerlendirilmesi sırasında tüm (arıtma vb.) alternatiflere ek olarak hiçbir şey yapmama alternatifinin de düşünülmesi gerekmektedir. $\mathrm{Bu}$ çalışmada elde edilen sonuçlar ışığında özellikle RBC ve MBR sistemleri ile gri suyun arıtılması tercih edilmesi durumunda bireysel kullanıcı tarafindan elde edilecek faydalar düşünüldüğünde hiçbir şeyin yapılmamasının daha fizıbıl olduğu söylenebilir. Bu sebeple, toplumsal faydanın da düşünüldüğü kapsamlı hesaplamalar da gerçekleștirilmelidir. Bu bağlamda yapılan öneriler Tartışma ve Sonuç kısmında detaylandırılmıştır.

\section{Tartışma ve Sonuç}

$\mathrm{Bu}$ çalışmada, gri suyun yeniden kullanımının hedeflendiği çok katlı binalarda ortaya çıkacak ilave altyapı inşaatı kaynaklı ilk yatırım maliyetleri ve çeşitli arıtma teknolojilerinin kullanılmasının yaratacağı işletme ve bakım maliyetleri üzerine çalışılmıştır. Gerçekleştirilen detaylı hesaplamalar sonucunda her katta az sayıda daire bulunduran yüksek katlı konutlar yerine yatay mimari yaklaşımı ile inșa edilmiș az katlı fakat nüfus yoğunluğunun yüksek olduğu konutların tercih edilmesinin bireysel kullanıcı açısından faydayı yüksek tutacağı söylenilebilir. Özellikle 160 ve daha fazla daire içeren binalarda fizıbıl olacağı söylenebilir. Bu tarz bir yaklașımın İstanbul dışındaki illerde de yer alan dikey ve/veya yatay mimariye sahip yüksek nüfus yoğunluğuna sahip olacak yeni site inşaatlarında da uygulanabilirliği yüksektir.

En fizibıl arıtma teknolojisi, NF sistemi olmuştur. En yüksek İBM kalemi, arıtılmış gri suyun üst katlara terfisi için gereken enerji sebebiyle ortaya çıkan maliyetlerdir. Dolayısı ile ara katlarda bir arıtma sistemi yerleşimi de düşünülmelidir. Bir diğer yenilikçi yaklaşım ise özel boru ağı tasarımı ve inşasıyla beraber daire içerisinde biyolojik kontaminasyon riski içermeyen atıksuların tuvaletlerin sifon haznelerine doğrudan iletimi ile yeniden kullanılmalarıdır. Sonuç olarak, İstanbul'da evsel 


\section{DEÜ FMD 23(67), 81-91, 2021}

atıksuyun yeniden kullanımı adına spesifik bir tarifenin bulunmaması da bireysel kullanıcıların faydasının düşük seviyelerde kalmasına sebep olduğundan gri suyun yeniden kullanımı konusundaki motivasyon eksik kalmaktadır. Bu bağlamda, bireysel fayda/maliyet analizine ek

\section{Kaynakça}

[1] Jefferson, B., Palmer, A., Jeffrey, P., Stuetz, R. and Judd, S., 2004. Grey water characterisation and its impact on the selection and operation of technologies for urban reuse. Water science and technology, 50(2), pp.157-164.

https://doi.org/10.2166/wst.2004.0113

[2] Jamrah, A., Al-Omari, A., Al-Qasem, L. and Ghani, N.A 2006. Assessment of availability and characteristics of greywater in Amman. Water international, 31(2), pp.210-220.

https://doi.org/10.1080/02508060.2006.9709671

[3] Ottoson, J. and Stenström, T.A., 2003, Faecal contamination of greywater and associated microbial risks. Water research, 37(3), pp.645-655. https://doi.org/10.1016/S0043-1354(02)00352-4

[4] Winward, G.P., Avery, L.M., Frazer-Williams, R., Pidou, M., Jeffrey, P., Stephenson, T. and Jefferson, B., 2008. A study of the microbial quality of grey water and an evaluation of treatment technologies for reuse. Ecological engineering, 32(2), pp.187-197. https://doi.org/10.1016/j.ecoleng.2007.11.001

[5] Friedler, E., Kovalio, R. and Galil, N.I., 2005. On-site greywater treatment and reuse in multi-storey buildings. Water science and technology, 51(10), pp.187-194.

https://doi.org/10.2166/wst.2005.0366

[6] Nolde, E., 2000. Greywater reuse systems for toilet flushing in multi-storey buildings-over ten years experience in Berlin. Urban water, 1(4), pp.275-284. https://doi.org/10.1016/S1462-0758(00)00023-6

[7] Pathan, A. A. (2015). Effect of flow rate and disc area increment on the efficiency of rotating biological contactor for treating greywater. Mehran University Research Journal of Engineering and Technology, 34(2), 99-106.

[8] Jabornig, S., 2014. Overview and feasibility of advanced grey water treatment systems for single households. Urban Water Journal, 11(5), pp.361369.

https://doi.org/10.1080/1573062X.2013.783086

[9] Fountoulakis, M.S., Markakis, N., Petousi, I. and Manios, T., 2016. Single house on-site grey water treatment using a submerged membrane bioreactor for toilet flushing. Science of the total environment, 551, pp.706-711. https://doi.org/10.1016/j.scitotenv.2016.02.057

[10] Lesjean, B. and Gnirss, R., 2006. Grey water treatment with a membrane bioreactor operated at low SRT and low HRT. Desalination, 199(1-3), pp.432-434. https://doi.org/10.1016/j.desal.2006.03.204

[11] Atanasova, N., Dalmau, M., Comas, J., Poch, M., Rodriguez-Roda, I., \& Buttiglieri, G. (2017). Optimized MBR for greywater reuse systems in olarak araştırmacıların toplumsal faydanın da hesaplandığı özel bir çalıșma gerçekleștirerek sonuçlarını paylaşması literatürün gelişmesi adına önerilebilir.

hotel facilities. Journal of environmental management, 193, 503-511.

[12] Pidou, M., Avery, L., Stephenson, T., Jeffrey, P., Parsons, S.A., Liu, S., Memon, F.A. and Jefferson, B., 2008. Chemical solutions for greywater recycling. Chemosphere, 71(1), pp.147-155. https://doi.org/10.1016/j.chemosphere.2007.10.04

[13] Li, F., Wichmann, K. and Otterpohl, R., 2009. Review of the technological approaches for grey water treatment and reuses. Science of the total environment, 407(11), pp.3439-3449. https://doi.org/10.1016/j.scitotenv.2009.02.004

[14] Humeau, P., Hourlier, F., Bulteau, G., Masse, A., Jaouen, P., Gerente, C., Faur, C. and Le Cloirec, P., 2011. Estimated costs of implementation of membrane processes for on-site greywater recycling. Water Science and Technology, 63(12), pp.2949-2956 https://doi.org/10.2166/wst.2011.617

[15] Wu, B. (2019). Membrane-based technology in greywater reclamation: A review. Science of the total environment, 656, 184-200.

[16] Maeda, M., Nakada, K., Kawamoto, K. and Ikeda, M., 1996. Area-wide use of reclaimed water in Tokyo, Japan. Water Science and Technology, 33(10-11), pp.51-57. https://doi.org/10.1016/0273-1223(96)00406-4

[17] Anadolu Ajansı, 2019. https://www.aa.com.tr/tr/turkiye/turkiyedehanehalkinin-yuzde-65i-cekirdek-aile/1473095, (Erisim Tarihi: 14.09.2019).

[18] Friedler, E. and Hadari, M., 2006. Economic feasibility of on-site greywater reuse in multi-storey buildings. Desalination, 190(1-3), pp.221-234. https://doi.org/10.1016/j.desal.2005.10.007

[19] Mutlu, B.K., Cantoni, B., Turolla, A., Antonelli, M., HsuKim, H. and Wiesner, M.R., 2018. Application of nanofiltration for Rare Earth Elements recovery from coal fly ash leachate: Performance and cost evaluation. Chemical Engineering Journal, 349, pp.309-317. https://doi.org/10.1016/j.cej.2018.05.080

[20] Tolga, E., \& Kahraman, C. (1994). Mühendislik ekonomisi. İTÜ.

[21] Alibaba Inc, 2019. https://www.alibaba.com/product-detail/840LLiquid-Chlorine-Cylinder-withLow_60705181153.html?spm=a2700.7724838.201 7115.27.557143b3aL0BDL\&s=p, (Erisim Tarihi: 14.09.2019)

[22] Davies, W.J., Le, M.S. and Heath, C.R., 1998. Intensified activated sludge process with submerged membrane microfiltration. Water Science and Technology, 38(4-5), pp.421-428. https://doi.org/10.1016/S0273-1223(98)00541-1 
DEÜ FMD 23(67), 81-91, 2021

[23] Pickering, K.D. and Wiesner, M.R., 1993. Cost model for low-pressure membrane filtration. Journal of Environmental Engineering, 119(5), pp.772-797. https://doi.org/10.1061/(ASCE)0733-

9372(1993)119:5(772)

[24] İSKİ, 2019. https://www.iski.istanbul/web/trTR/musteri-hizmetleri/su-birim-fiyatlari, (Erişim Tarihi: 14.09.2019).

[25] Emlak Sayfası, 2019.

https://www.emlaksayfasi.com.tr/bolgeraporlari/fikirtepe-konut-fiyatlari-metrekarede-10bin-tl-yi-asti-h39009.html, (Erişim Tarihi: 14.09.2019). 